\title{
STUDI KUALITAS DAYA UNTUK BERBAGAI VARIASI LETAK KAPASITOR PADA INSTALASI TENAGA
}

\author{
Muh.Yusuf.T ${ }^{1)}$, Ahmad Rizal Sultan ${ }^{2)}$, Sarma Thaha ${ }^{3)}$ \\ Teknik ElektroPoliteknik Negeri Ujung Pandang \\ Email:Muhyusuf041995@gmail.com
}

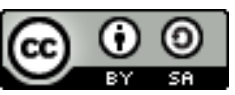

Abstrak

Salah satu permasalahan yang umumnya terjadi dalam proses penyaluran energi listrik yaitu rendahnya faktor daya pada sistem khususnya jika digunakan pada tingkat industri, Industri pada umumnya rata-rata menggunakan beban yang bersifat induktif sehingga dalam penerapannya diperlukan daya reaktif sebagai suplay beban induktif untuk memenuhi kebutuhan pada sistem jaringan distribusi tenaga listrik. Faktor daya rendah dapat mengakibatkan kualitas daya terganggu, kualitas daya yang buruk maka akan berdampak mempengaruhi sistem secara keseluruhan dan dapat merusak peralatan maupun sistem tersebut, Sementara kualitas daya yang baik dapat mengoptimalkan kinerja system jaringan distribusi,peralatan dan beban yang terpasang. Penelitian ini bertujuan untuk memperbaiki kualitas daya pada sistem instalasi tenaga dengan mengambil parameter yang dijadikan sebagai rujukan yaitu nilai faktor daya pada system. Adapun standar parameter sesuaidengan standar yang ditetapkan oleh PUIL dan IEEE. Dalam perbaikan faktor daya terdapat beberapa metode yang dapat digunakan yaitu metode Individual kompensasi, Grup kompensasi, Global kompensasi. Dari beberapa hasil tersebut dapat disimpulkan bahwa untuk perbaikan faktor daya yang efisien dalam penyaluran daya reaktif maka digunakan kompensator dengan metode individual kompensasi. Ketiga metode diatas dapat dibuktikan dengan menggunakan salah metode simulasi di aplikasi ETAP.

Keywords: Kualitas daya, perbaikan faktor daya, kinerja sistem, software ETAP versi 12.6

\section{PENDAHULUAN}

Dalam sistem tenaga listrik, terdapat tiga jenis daya yaitu daya semu, daya aktif, dan daya reaktif. Dalam Penerapan pada umunya ketiga daya diatas dapat ditinjau dari kualitas daya dengan mengacu pada beberapa tolak ukur termasuk kualitas daya. Kualitas daya yang baik dapat mengefisienkan proses distribusi tenaga listrik yang disuplai dari produsen ke konsumen atau dari PHB ke beban/peralatan. Adapun hal-hal yang mempengaruhi kebutuhan Kualitas daya listrik seperti jumlah beban, jenis beban, jenis penghantar maupun jarak antara sumber listrik dengan beban, Namun didalam penelitian ini hanya membahas mengenai perbaikan faktor daya pada sistem dengan mempertimbangkan hal-hal diatas. Untuk menjaga sistem tetap stabil maka perlu diperhatikan keseimbangan faktor daya dalam sistem karena semakin tinggi kebutuhan daya reaktif beban maka faktor daya akan semakin rendah, begitupula ketika daya reaktif beban kecil maka faktor daya akan tinggi. Untuk beban rumah tangga, kebutuhan daya reaktif masih kecil dan dianggap normal, sedangkan pada beban industri yang menggunakan banyak beban yang bersifat induktif seperti motor listrik dan sebagainya yang kebutuhan daya reaktifnya cukup tinggi sehingga beban/peralatan industri yang seharusnya berfungsi secara maksimal kinerjanya menurun akibat suplay daya reaktif yang tidak efisien. Untuk memperbaiki faktor daya tersebut, salah satu metode yang akan digunakan ialah dengan menambahkan kapasitor bank sebagai kompensator daya reaktif. Penambahan kapasitor pada beban motor berperan sebagai penyuplai daya reaktif yang dibutuhkan oleh motor sehingga beban motor tersebut tidak lagi menarik banyak daya reaktif dari sistem yang akan berdampak pada pembangkit. Dalam penelitian ini akan dilakukan penelitian eksperimental dengan meletakkan kapasitor kompensator di posisi dan letak jarak yang berbeda untuk melihat kondisi tanggapan sistem (nilai faktor daya) terhadap kondisi beban tersebut pada instalasi tenaga (motor listrik).

\section{KAJIAN LITERATUR}

Kualitas daya merupakan hal penting dalam sistem tenaga listrik. Sistem tenaga listrik dengan kualitas daya yang baik berdampak pada terjaganya kontinyuitas pelayanan daya listrik. Disamping itu mempengaruhi pula terpeliharanya keselamatan manusia dan peralatan dari sengatan listrik serta dapat menghemat energi listrik maupun biaya penggunaan listrik. Kualitas daya adalah syarat umum yang menggambarkan karakteristik parameter catuan seperti arus, tegangan, frekuensi dan bentuk gelombang dibandingkan dengan standar atau harapan/tuntutan (Heydt,1991).

\section{A. Faktor Daya}

Faktor daya $(\operatorname{Cos} \varphi)$ dapat didefinisikan sebagai perbandingan antara daya aktif (Watt) dan daya semu (VA) yang digunakan dalam listrik arus bolak balik. Faktor daya dapat juga didefenisikan sebagai beda sudut antara nilai tegangan (V) dan nilai arus (I) yang biasanya dinyatakan dalam besaran $\cos \varphi$. Hal ini dapat dinyatakan seperti pada Gambar 1 : 


\section{e-ISSN 2656-0143}

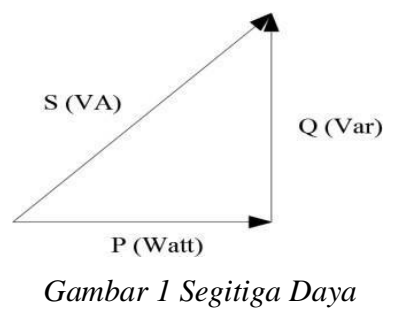

\section{I.A Perbaikan Faktor Daya}

Perbaikan faktor daya umumnya adalah penambahan komponen kapasitor sebagai pembangkit daya reaktif yang memungkinkan untuk mensuplai kebutuhan kVAR pada beban-beban induktif. Untuk merencanakan suatu sistem dalam memperbaiki faktor daya, dapat dipergunakan suatu konsep yaitu kompensator ideal, dimana sistem ini dapat dihubungkan pada titik penyambungan secara paralel dengan beban dan memenuhi 3 fungsi utama, yaitu memperbaiki faktor daya mendekati nilai 1 (unity power factor), mengurangi atau mengeliminasi regulasi tegangan dan menyeimbangkan arus beban dan tegangan fasa. Untuk memenuhi kebutuhan daya reaktif yang efektif dan efisien, maka perlu dilakukan pemilihan sumber daya reaktif untuk perbaikan faktor daya (Stevenson, 1993).,

\section{II.A. Kapasitor Bank untuk perbaikan factor daya}

Sebuah kapasitor variabel yang terpasang paralel pada suatu beban induktif dapat diatur sedemikian rupa sehingga arus yang mendahului pada kapasitor menjadi tepat sama besar dengan komponen arus pada beban induktif yang tertinggal $90^{\circ}$ terhadap tegangan. Jadi arus total sefasa dengan tegangan. Rangkaian induktif masih memerlukan daya reaktif positif, tetapi daya reaktif nettonya nol. Inilah alasannya mengapa insinyur sistem tenaga lebih suka menganggap kapasitor sebagai pencatu daya reaktif kepada beban induktif (Stevenson, 1993).,

Untuk memperbaiki faktor daya dapat meningkatkan nilai dari $\cos \varphi_{1}$ menjadi $\cos \varphi_{2}$ dengan tingkat distorsi yang rendah dan tidak terjadi resonansi pada impedansi bus-bus utama. Berdasarkan atas pengukuran pemakaian beban puncak sebelum dilakukan pemasangan kompensator daya reaktif tambahan berupa kapasitor bank dapat ditentukan kebutuhan daya aktif dan daya reaktifnya;

$\operatorname{Cos} \varphi(\mathrm{pf})={ }_{T}^{P}$

$$
=\frac{\text { V.I.Cos } \varphi}{V \cdot I}
$$

dimana : $\operatorname{Cos} \varphi=$ Faktor Daya

$$
\begin{aligned}
& \mathrm{P}=\text { Daya Aktif }(\mathrm{kW}) \\
& \mathrm{S}=\text { Daya Semu }(\mathrm{kVA})
\end{aligned}
$$

V.I.Cos $\varphi$ adalah total daya aktif (P total) pada saat operasi beban penuh maka:

$$
\begin{aligned}
& \text { Daya Aktif }(\mathrm{P})=\sqrt{3} \times \mathrm{V} \times \mathrm{I} \times \cos \varphi \\
& \begin{aligned}
\text { Daya Reaktif }(\mathrm{Q}) & =\sqrt{k V A^{2}-k W^{2}} \\
& =\mathrm{kVASin} \varphi \\
& =\mathrm{kW} \operatorname{Tan} \varphi
\end{aligned} \\
& \text { DayaSemu }(\mathrm{S})=\sqrt{k W^{2}+k V A R^{2}}
\end{aligned}
$$

$$
=\frac{k W}{\cos \varphi}
$$

Untuk meningkatkan nilai $\operatorname{Cos} \varphi_{2}$ mendekati nilai ideal yaitu 1 (Unity Power faktor). Dalam hal ini, dengan melihat karakteristik beban yang fluktuatif maka target perbaikan faktor daya adalah dari $\operatorname{Cos} \varphi_{1}$ menjadi $\operatorname{Cos} \varphi_{2}$. Sehingga kebutuhan daya reaktifnya akan berubah menjadi :

$\mathrm{Q}_{\mathrm{b}}=\mathrm{P} \tan \varphi_{1}$

$\mathrm{Q}_{\mathrm{t}}=\mathrm{P} \tan \varphi_{2}$

Sehingga :

$\mathrm{Q}_{\mathrm{C}}=\mathrm{Q}_{\mathrm{b}}-\mathrm{Q}_{\mathrm{t}}$

$\mathrm{C}=\frac{Q c}{2 \cdot \pi \cdot f \cdot V^{2} \cdot 10^{-6}}$

Dimana : $\mathrm{Q}_{\mathrm{b}}=$ Daya reaktif sebelum perbaikan $(\mathrm{VAR})$

$\mathrm{Q}_{\mathrm{t}}=$ Daya reaktif setelah perbaikan

(VAR)

(VAR)

$$
\mathrm{Q}_{\mathrm{C}}=\text { Daya reaktif yang dikompensasi }
$$

$$
\mathrm{C}=\text { Kapasitansi kapasitor }(\mu \mathrm{F})
$$

Dengan demikian untuk menaikkan faktor daya dari Cos $\varphi_{1}$ menjadi Cos $\varphi_{2}$ diperlukan kapasitor bank sebesar $\mathrm{C}$ $(\mu \mathrm{F})$. Untuk lebih jelasnya dapat dilihat diagram Gambar 2

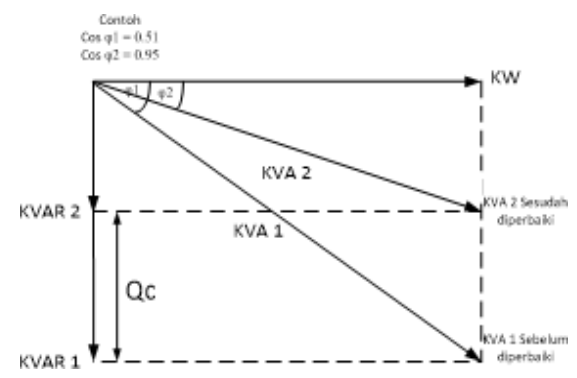

Gambar 2 Contoh diagram daya untuk menentukan daya kapasitor

\section{B. METODE PENELITIAN}

Penelitian ini dimaksudkan untuk mengurangi terjadinya faktor daya rendah ataupun tinggi (lagging/leading) pada sistem jaringan listrik, konsep rancangan megacu pada variasi letak kapasitor dengan beberapa metode yaitu metode: Kompensasi Global, Kompensasi Grup, dan Kompensasi Individu. Adapun alat dan bahan yang digunakan tabel 1;

\begin{tabular}{|l|l|c|}
\hline No & \multicolumn{1}{|c|}{ Alat dan bahan } & Jumlah \\
\hline 1 & Cos $\varphi$ meter & 1 buah \\
\hline 2 & Multitester & 1 buah \\
\hline 3 & Power Quality Meter(PQM) & 1 buah \\
\hline 4 & Metrel & 1 buah \\
\hline 5 & Panel & 3 buah \\
\hline 6 & Motor listrik & 5 buah \\
\hline 7 & Obeng (+/-) & 1 buah \\
\hline 8 & Tang kombinasi & 1 buah \\
\hline 9 & Tang potong & 1 buah \\
\hline 10 & Isolasi & 1 buah \\
\hline 11 & Terminal & 2 unit \\
\hline 12 & Kapasitor Bank & 8 buah \\
\hline 13 & Kabel NYM 3x2,5 & Secukupnya \\
\hline
\end{tabular}


Untuk pengumpulan data digunakan metode kualitatif dan kuantitatif.

\section{HASIL DAN PEMBAHASAN}

Dalam pengambilan data maka digunakan table acuan sebagai langkah awal untuk melakukan pengambilan data mangacu pada standar yang ada seperti yang ditetapkan oleh IEEE (Institute of Electrical and Electronics Engineers) sebagai berikut:

Tabel 2 Tabel STD IEEE 446-1995.

\begin{tabular}{cll}
\hline No. & \multicolumn{1}{c}{ Parameter } & \multicolumn{1}{c}{ Range } \\
\hline 1 & Voltage limitsteady-state(all phase) & $+6 \%,-13 \%$ \\
& & surge $+15 \%$ for 0,5 s maximum Sag- \\
& & $18 \%$ for 0,5 s maximum Transient over \\
2 & voltage disturbances (all phases) & voltage $150-200 \%$ for $0.2 \mathrm{~ms}$ \\
3 & harmonic content & $5 \%$ maximum with equipment operating \\
4 & electromagnetic compatibility & $1 \mathrm{v} / \mathrm{m}$ maximum \\
5 & frequency limits & $60 / 50 \mathrm{~Hz} \pm 0,5$ \\
6 & frequency rate of change & $1 \mathrm{~Hz} / \mathrm{s}$ (slew rate) \\
7 & three-phase voltage unbalance & $2,5 \%$ of arithmetic average \\
8 & three-phase load unbalance & $5-20 \%$ maximum for any one phase \\
\hline Institute of Electrical and Electronics Engineers $($ IEEE
\end{tabular}

Berikut gambar simulasi sesuai dengan data nama plate pada beban dan hasil perhitungan arus nominal pada gambar 3

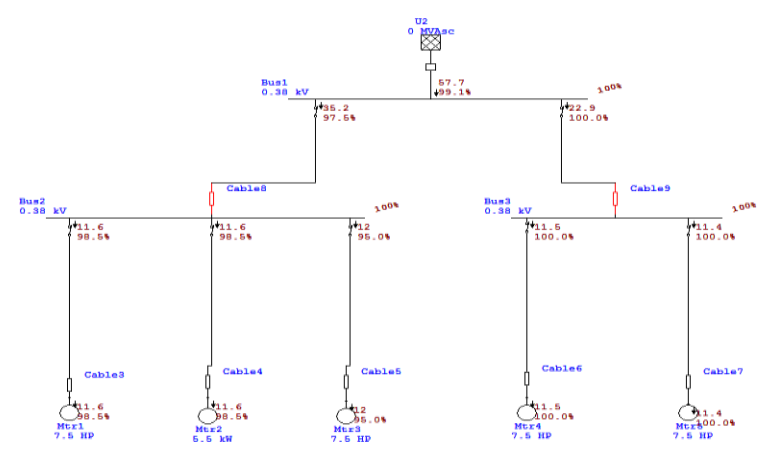

Gambar 3 Gambar simulasi sesuai dengan name plate.

Berikut merupakan hasil pengukuran data beban dengan alat ukur Power Quality Meter(PQM), adapun data berikut mencakup data arus, tegangan, daya, frekuensi, dan harmonisa dapat dilihat pada tabel 4

Tabel 4 Data Pengukuran Tiap Beban (Motor) berupa Arus, Tegangan, Frekuensi, berikut tabel pengukuran;

\begin{tabular}{|c|c|c|c|c|c|}
\hline \multicolumn{7}{|c|}{ Arus } \\
\hline & M1 & M2 & M3 & M4 & M5 \\
\hline Ia & 5 & 6 & 5 & 5 & 7 \\
\hline Ib & 4 & 5 & 4 & 4 & 6 \\
\hline Ic & 5 & 6 & 6 & 6 & 7 \\
\hline Iavg & 5 & 6 & 5 & 5 & 7 \\
\hline & & & & & \\
\hline
\end{tabular}

\begin{tabular}{|c|c|c|c|c|c|}
\hline \multicolumn{7}{|c|}{ Tegangan } \\
\hline & M1 & M2 & M3 & M4 & M5 \\
\hline Va-n & 232 & 224 & 233 & 231 & 232 \\
\hline Vb-n & 223 & 212 & 224 & 223 & 223 \\
\hline Vc-n & 231 & 224 & 232 & 232 & 232 \\
\hline Vavg L-N & 228 & 221 & 229 & 231 & 229 \\
\hline Va-b & 393 & 378 & 394 & 393 & 393 \\
\hline Vb-c & 395 & 380 & 396 & 396 & 396 \\
\hline Vc-a & 400 & 387 & 402 & 401 & 400 \\
\hline Vavg L-L & 396 & 382 & 397 & 396 & 396 \\
\hline
\end{tabular}

\begin{tabular}{|c|c|c|c|c|c|}
\hline \multicolumn{6}{|c|}{ Frekuensi } \\
\hline & M1 & M2 & M3 & M4 & M5 \\
\hline F & $49,94 \mathrm{~Hz}$ & $49,98 \mathrm{~Hz}$ & $50,12 \mathrm{~Hz}$ & $50,06 \mathrm{~Hz}$ & $\begin{array}{c}49,97 \\
\mathrm{~Hz}\end{array}$ \\
\hline
\end{tabular}

\section{Perhitungan kebutuhan kapasitas kapasitor}

Kebutuhan daya reaktif Panel Induk untuk perbaikan faktor daya 0,95 .

$$
\begin{aligned}
& \operatorname{Cos} \phi_{1}=0,43 \\
& \operatorname{Cos} \phi_{2}=0,95 \\
& =64,532^{\circ} \\
& =1,125 \mathrm{rad} \text {. } \\
& =0,317 \mathrm{rad} \text {. } \\
& =18,194^{\circ} \\
& \mathrm{Qc}=\mathrm{kW}\left(\tan \phi_{1}-\tan \phi\right)_{2} \\
& =27,9\left(\tan \left(64,532^{\circ}\right)-\tan \left(18,194^{\circ}\right)\right) \\
& =27,9(2,099-0,328) \\
& =27,9(1,771) \\
& =49,426 \mathrm{kVar} \\
& \mathrm{C}=\frac{Q c}{2 . \pi \cdot f \cdot V^{2} 10^{-6}} \\
& =\frac{49,426}{2.3,14.50 .380^{2} 10^{-6}} \\
& =\frac{49,426=1090 \mu \mathrm{F}}{45,3416}
\end{aligned}
$$

Tabel 5 Nilai daya reaktif dan kapasitas kapasitor

\begin{tabular}{clcc} 
No. & Nama & kVar & C \\
\hline 1 & Motor 1 & 21,856 & $482 \mu \mathrm{F}$ \\
\hline 2 & Motor 2 & 22,583 & $498 \mu \mathrm{F}$ \\
\hline 3 & Motor 3 & 21,856 & $482 \mu \mathrm{F}$ \\
\hline 4 & Motor 4 & 20,814 & $454 \mu \mathrm{F}$ \\
\hline 5 & Motor 5 & 24,235 & $534 \mu \mathrm{F}$ \\
\hline 6 & Panel Induk & 49,426 & $1090 \mu \mathrm{F}$ \\
\hline
\end{tabular}

Berikut gambar 4 Grafik hasil perbandingan daya reaktif 


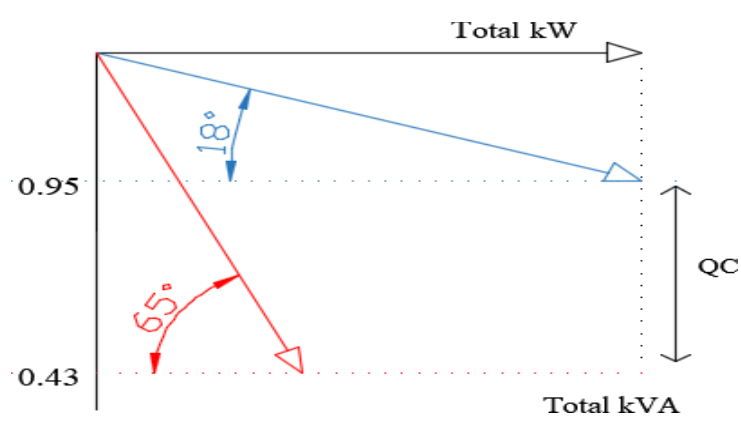

Gambar 4 Grafik hasil perbandingan daya reaktif

Berikut gambar 5 hasil simulasi Aplikasi ETAP menggunakan metode Individual Compensation

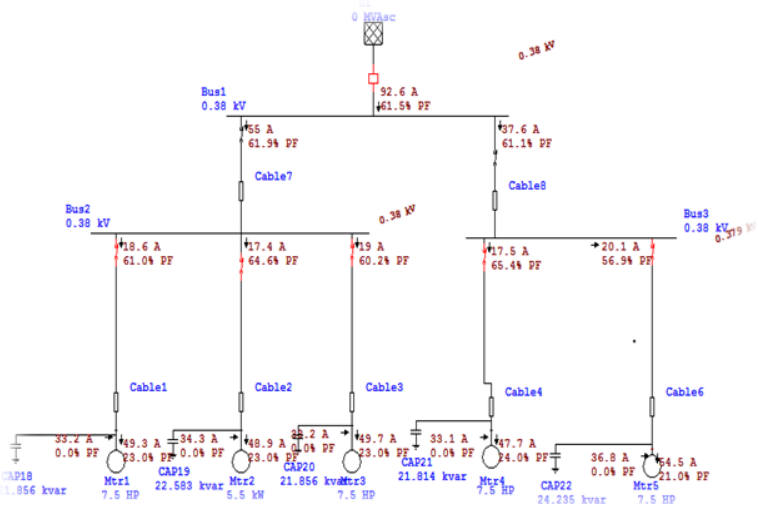

Gambar 5 Metode Individual Compensation

Berikut gambar 6 hasil simulasi Aplikasi ETAP menggunakan metode Grup Compensation

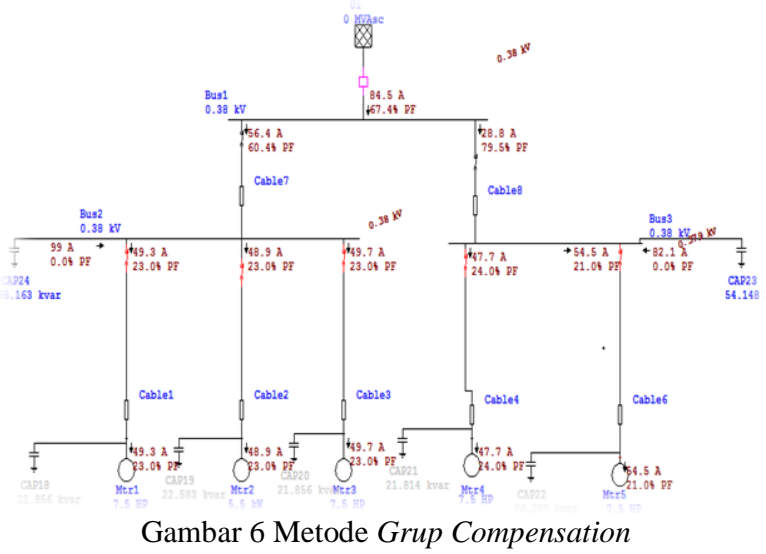

Berikut gambar 7 hasil simulasi Aplikasi ETAP menggunakan metode Global Compensation

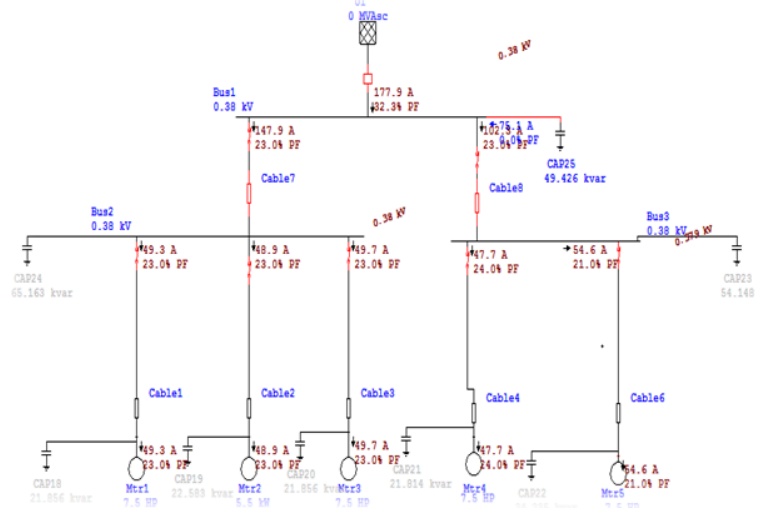

Gambar 7 Metode Global Compensation

\section{KESIMPULAN}

Dari pengujian yang dilakukan dengan menggunakan tiga metode, yaitu metode kompensasi individual, kompensasi grup, dan kompensasi global.

Metode individual memberikan hasil dimana ketika faktor daya beban baik, maka seluruh sistem jaringan faktor dayanya akan menjadi baik sedangkan,

Pada metode kompensasi grup hanya memperbaiki faktor daya dari bus cabang ke bus induk.

Metode

kompensasi global hanya memperbaiki faktor daya pada induk namun hasilnya tidak maksimal karena disebabkan oleh faktor daya yang diperbaiki merambat ke jaringan produsen.

\section{UCAPAN TERIMA KASIH}

Pada kesempatan ini penulis menyampaikan penghargaan dan ucapan terima kasih yang sebesarbesarnya kepada:

1. Bapak Dr.Ir.H Hamzah Yusuf, M.S., selaku Direktur Politeknik Negeri Ujung Pandang.

2. Ibu Dr.Ir.Hafsah Nirwana,M.T. selaku Ketua Jurusan Teknik Elektro.

3. Bapak Sofyan, S.T., M.T. selaku Ketua Program Studi D4 Teknik Listrik

4. Bapak Ahmad Rizal Sultan, S.T., M.T., Ph.D.sebagai Pembimbing I dan Ibu Sarma Thaha, S.T.,M.T. sebagai Pembimbing II yang telah mencurahkan waktu, tenaga, materi dan kesempatannya untuk mengarahkan penulis dalam menyelesaikan skripsi ini.

5. Para Dosen dan Staf Jurusan Teknik Listrik yang telah banyak membantu dari awal hingga akhir pembuatan skripsi ini.

6. Saudara-saudara seperjuanganku dan seluruh pihak yang telah membantu dalam menyelesaikan skripsi ini. Ucapan terimah kasih dan penghargaan juga disampaikan kepada keluarga terutama orang tua yang memberikan doa dan dukungan selama penyusunan laporan skripsi. Semoga skripsi ini dapat memberikan nilai tambah dan manfaat bagi kita semua. Aamiin 


\section{REFERENSI}

[1] Badan standar IEEE .1995.Institute of Electrical and Electronics Engineers 446.

[2] Badan Standarisasi Nasional. 2011. Persyaratan Umum Instalasi Listrik.

[3] Gonen, T., 1986., Electric Power Distribution System Engineering,. Mc Graw-Hill Book Company.

[4] Harten, P.V. 1991., "Instalasi Listrik Arus Kuat IIl".Bina Cipta, Bandung.

[5] Thompson, F.G.1992. “Electrical Installation and Workshop Technology", Longman Scientific \& Technical. 